\title{
Phospholipase D activity is required for dimorphic transition in Candida albicans
}

\author{
Nealoo McLain ${ }^{1}$ and Joseph W. Dolan ${ }^{2}$ \\ Author for correspondence: Joseph W. Dolan. Tel: +1 803792 1904. Fax: +1 8037922464. \\ e-mail : dolanjw@musc.edu
}

\begin{abstract}
Molecular and Cellular Biology and Pathobiology Program ${ }^{1}$ and Department of Microbiology and Immunology2, Medical University of South Carolina, Charleston, SC 29425, USA
\end{abstract}

\begin{abstract}
Candida albicans is an opportunistic pathogen that causes significant morbidity and mortality in immunocompromised patients. In this report, the presence of a phospholipase D (PLD) activity in C. albicans, designated CaPLD1, is demonstrated. This is the first description of PLD activity in this organism. CaPLD1 activity was stimulated by inducers of dimorphic transition. Furthermore, transition was stimulated by the addition of exogenous PLD to cells. The addition of 1-propanol to the medium, which resulted in the production of phosphatidylpropanol by CaPLD1 at the expense of the usual product phosphatidic acid, delayed the yeast to hypha transition. These results suggest that CaPLD1 may be an important regulator of dimorphic transition in C. albicans.
\end{abstract}

Keywords: Candida albicans, phospholipase D, dimorphic transition

\section{INTRODUCTION}

Phospholipases have emerged as significant components of numerous signal transduction pathways in a wide variety of organisms. Phospholipase D (PLD) activity has been identified in mammals, plants, bacteria (Heller, 1978) and fungi (Ella et al., 1995). The preferred substrate of PLD is the phospholipid phosphatidylcholine, which is hydrolysed to phosphatidic acid. Phosphatidic acid itself can function as a second messenger (Amsterdam et al., 1994; Moritz et al., 1992; Ha \& Exton, 1993) and may regulate the production of phosphatidylinositol 4,5-bisphosphate (Jenkins et al., 1994). Additionally, phosphatidic acid can be hydrolysed to diglyceride by the subsequent action of phosphatidic acid phosphohydrolase (Morlock et al., 1991; Wu et al., 1993). It has been suggested that diglyceride generated by the sequential action of PLD and phosphatidic acid phosphohydrolase can serve to augment the production of diglyceride by phospholipase C (Exton, 1990). The formation of phosphorylcholine by the sequential action of PLD and choline kinase leads to the activation of Raf-1 kinase and mitogen-activated protein kinases (Jimenez et al., 1995). A defining

\footnotetext{
Abbreviations: BODIPY, 4,4-difluoro-5,7-dimethyl-4-bora-3a,4a-diaza-sindacene; BDG, BODIPY-diglyceride; BPA, BODIPY-phosphatidic acid; BPBu, BODIPY-phosphatidylbutanol; BPC, 2-decanoyl-1-(O-[11-(4,4-difluoro-5,7-dimethyl-4-bora-3a,4a-diaza-s-indacene-3-propionyl)amino]indecyl)-sn-glycerol-3-phosphocholine; BPOR, BODIPY-phosphatidylalcohols; PLD, phospholipase D.
}

characteristic of PLD is the ability to perform a transphosphatidylation reaction in the presence of primary alcohols (Heller, 1978; Kanfer, 1980). In this reaction, the phosphate group of phosphatidylcholine is transferred to the alcohol to produce phosphatidylalcohol, rather than to water to produce phosphatidic acid.

Both soluble and membrane-associated forms of PLD have been described with a wide range of molecular masses (Heller, 1978; Ella et al., 1995; Hammond et al., 1995; Wang et al., 1994). Several mechanisms have been implicated in the regulation of PLD in mammals. The analysis of regulatory mechanisms has been complicated by the possible existence of multiple isoforms of PLD, each form potentially regulated differently (see, for example, Song \& Foster, 1993). Isoforms of PLD can be regulated by protein kinase C (Conricode et al., 1992; Balboa \& Insel, 1995; Lopez et al., 1995) and GTPbinding proteins. Evidence supports a role in PLD regulation for ADP-ribosylation factor (Brown et al., 1993; Cockcroft et al., 1994), Rho (Ohguchi et al., 1995), Ras (Carnero et al., 1994) and Ral (Jiang et al., 1995) small GTP-binding proteins. Phosphatidylinositol 4,5bisphosphate stimulates PLD activity (Liscovitch et al., 1994; Massenburg et al., 1994). Oleate has been found to stimulate some forms of PLD (Massenburg et al., 1994) and to inhibit other forms (Waksman et al., 1996).

The gene encoding PLD in Saccharomyces cerevisiae, designated PLD1, has been cloned (Honigberg et al., 1992; Rose et al., 1995). The enzyme is a $195 \mathrm{kDa}$ 
membrane-associated protein that shares limited homology with the protein from castor bean and at least one isoform of the mammalian enzyme (Hammond et al., 1995). As with the mammalian PLDs, the Saccharomyces enzyme (ScPLD1) is capable of performing the transphosphatidylation reaction with alcohols (Ella et al., 1995), is stimulated by phosphatidylinositol 4,5-bisphosphate (Waksman et al., 1996; Rose et al., 1995) and inhibited by oleate and chelators of divalent cations (Waksman et al., 1996). Growth on non-glucose carbon sources stimulates ScPLD1 activity (Ella et al., 1995; Waksman et al., 1996). The level of ScPLD1 activity increases rapidly when diploid Saccharomyces cells are suspended in sporulation medium (Ella et al., 1995). Consistent with this activation, ScPLD1 is required for sporulation: homozygous null mutants are unable to sporulate while heterozygous strains can sporulate (Ella et al., 1996; Waksman et al., 1996; Rose et al., 1995). Although loss of activity results in a decreased growth rate on non-glucose carbon sources, ScPLD1 activity is not essential for viability. Recently, a second PLD has been characterized biochemically in S. cerevisiae (Mayr et al., 1996; Waksman et al., 1997) and designated PLD2. PLD2 activity can be detected in a pld1 mutant and is stimulated by calcium. PLD2 preferentially utilizes phosphatidylethanolamine rather than phosphatidylcholine and is unable to catalyse a transphosphorylation reaction with primary alcohols (Waksman et al., 1997). This finding suggests that in S. cerevisiae, as with higher eukaryotes, more than one isoform of PLD may be present.

Here we report the characterization of a PLD activity in Candida albicans, an opportunistic human pathogen. This is the first time PLD activity has been reported in this organism. Candidal infections are the cause of significant morbidity and mortality in patients with cancer or AIDS and occur at a significant rate in immunosuppressed transplant recipients and patients undergoing chemotherapy. Due to the growing medical significance of Candida species, there is a need to understand the basic physiology and the manner in which the organism senses and responds to its environment. Of particular interest are the stimuli that induce dimorphic transition, the morphology change from yeasts to hyphae. Data are presented that indicate PLD is important for this transition.

\section{METHODS}

Strain and media. Candida albicans ATCC strain 28367 was used in all experiments. Stocks were maintained on Sabouraud agar (Difco) and grown on YPD broth (Sherman, 1991). When different carbon sources were used, the base medium was YEP (Sherman, 1991) with the indicated carbon sources added to $2 \%(\mathrm{w} / \mathrm{v})$.

Preparation of extracts. Membranes were prepared as described previously by Ella et al. (1995) with the following change: the lysis buffer contained $20 \mathrm{mM} \mathrm{KH} \mathrm{PO}_{4} / \mathrm{K}_{2} \mathrm{HPO}_{4}$ (pH 7.0), $150 \mathrm{mM} \mathrm{NaCl}, 10 \mathrm{mM}$ EGTA, $2 \mathrm{mM}$ EDTA, $2 \mathrm{mM}$ DTT, $5 \mu \mathrm{g}$ leupeptin $\mathrm{ml}^{-1}, 1 \mu \mathrm{g}$ pepstatin $\mathrm{ml}^{-1}$ and $0 \cdot 1 \mathrm{mM}$ PMSF.

CaPLD1 assay conditions. In vitro assays using a fluorescent substrate were performed as described previously by Ella et al. (1995) with the following changes. The substrate is a BODIPYlabelled analogue of glycerophosphocholine, 2-decanoyl-1(O-[11-(4,4-difluoro-5,7-dimethyl-4-bora-3a,4a-diaza-sindacene-3-propionyl) amino] indecyl)-sn-glycerol-3-phosphocholine (BPC) (Molecular Probes). The final reaction buffer contained $40 \mathrm{mM} \mathrm{KH}_{2} \mathrm{PO}_{4} / \mathrm{K}_{2} \mathrm{HPO}_{4}(\mathrm{pH} \mathrm{7 \cdot 0)}, 150 \mathrm{mM}$ $\mathrm{NaCl}, 5 \mathrm{mM}$ EGTA, $1 \mathrm{mM}$ EDTA, $1 \mathrm{mM}$ DTT, $0.15 \mathrm{mM}$ Nonidet P-40, 1\% (v/v) alcohol and $0.1 \mathrm{mM}$ BPC. Each reaction contained $5 \mu \mathrm{g}$ membrane protein as determined by a Bradford assay. The products were analysed and quantified with a FluorImager (Molecular Dynamics). The enzyme activity is presented as relative activity with respect to an appropriate control reaction. The fluorescence present in the product spots on the TLC plate was quantified with a Molecular Dynamics FluorImager and the quantity of fluorescence in the product spots from the control reaction was set to $1 \cdot 0$. The quantity of fluorescence in the product spots of the experimental reactions was then normalized to the value from the control reaction to obtain the relative activity. Relative activity values represent the mean of at least two independent experiments. Except where indicated, the fluorescence representing BODIPY-phosphatidic acid (BPA) and BODIPYphosphatidylalcohols (BPOR) produced in each reaction has been combined.

Assay of CaPLD1 activity during dimorphic transition. A culture of cells growing exponentially in YPD at $30^{\circ} \mathrm{C}$ was split into three cultures. Foetal bovine serum (FBS) was added to all three to a final concentration of $25 \%(\mathrm{v} / \mathrm{v}\rangle$. 1-Propanol was added to one culture to a final concentration of $0.5 \%$ $(\mathrm{v} / \mathrm{v})$ and 2-propanol was added to a second culture to a final concentration of $0.5 \%(\mathrm{v} / \mathrm{v})$. The three cultures were incubated at $39^{\circ} \mathrm{C}$ with agitation to induce the formation of germ tubes. Samples were taken at indicated time-points, sonicated to disrupt clumps, and examined microscopically with a haemocytometer for the appearance of germ tubes. For the assays of endogenous CaPLD1 activity during transition, a culture of exponentially growing cells at $5 \times 10^{6} \mathrm{cells} \mathrm{ml}^{-1}$ in YPD at $30^{\circ} \mathrm{C}$ was supplemented with either FBS to a final concentration of $25 \%(\mathrm{v} / \mathrm{v})$ or $N$-acetylglucosamine to a final concentration of $2.5 \mathrm{mM}$ and was shifted to $39^{\circ} \mathrm{C}$. Approximately $2 \times 10^{7}$ cells were sampled at each indicated time-point and whole-cell extracts were assayed for CaPLD1 activity as described above.

\section{RESULTS}

\section{C. albicans possesses a membrane-associated PLD}

A whole-cell extract was prepared from C. albicans strain ATCC 28367 and separated into a soluble cytosolic fraction and a particulate membrane fraction by ultracentrifugation. Each fraction was assayed in vitro for the presence of PLD activity using a fluorescent analogue of phosphatidylcholine, designated BPC. There was no detectable PLD activity in the cytosolic fraction while the membrane fraction produced BPA, BODIPY-phosphatidylbutanol (BPBu) and BODIPYdiglyceride (BDG) (Fig. 1). A control reaction containing commercially available peanut PLD was included to provide standards for the products. The presence of BPBu indicated that CaPLD1 was capable of performing the hallmark transphosphatidylation reaction with butanol. The transphosphatidylation reaction was examined in greater detail by assaying the ability of CaPLD1 


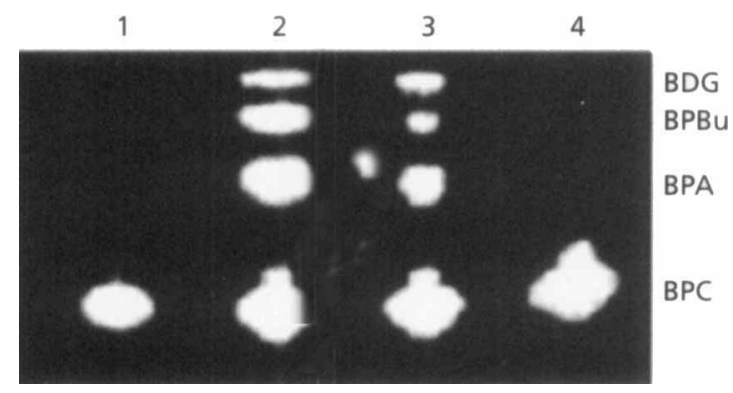

Fig. 1. C. albicans possesses a membrane-associated PLD. Extracts of $C$. albicans cells were fractionated into membranes and soluble cytosol and assayed for PLD activity as described in Methods. Lanes: 1, BPC in reaction buffer without a source of PLD; 2, 5 units peanut PLD (Sigma) present; 3, Candida membranes; 4, Candida cytosol. The separation was performed on plastic-backed silica gel 60 plates (EM Science).

to utilize a variety of alcohols. As has been seen with mammalian and $S$. cerevisiae PLDs, CaPLD1 formed BPOR with several primary alcohols ranging from methanol to butanol (Fig. 2). CaPLD1 did not efficiently use the branched-chain alcohols 2-propanol and 2methyl-1-propanol. In contrast, CaPLD1 was able to utilize the branched-chain alcohol 3-methyl-1-butanol very efficiently.

\section{CaPLD1 is regulated by carbon source}

ScPLD1 is regulated by growth medium with growth on non-glucose carbon sources resulting in increased activity (Ella et al., 1995; Waksman et al., 1996). To determine whether CaPLD1 was also regulated by carbon source, membranes were prepared from stationary phase cultures of $C$. albicans grown on rich medium with glucose, galactose, acetate or glycerol as carbon sources. Assays indicated that the carbon source affects CaPLD1. Relative to the level of activity in extracts from cells grown on glucose (1.00), CaPLD1 was stimulated by growth on galactose $[1 \cdot 22 \pm 0 \cdot 17( \pm$ SEM $)]$ and acetate $(1 \cdot 41 \pm 0 \cdot 18)$ but was reduced in cells grown on glycerol $(0 \cdot 61 \pm 0 \cdot 13)$. The effect of additional carbon sources which $C$. albicans can utilize was not determined.

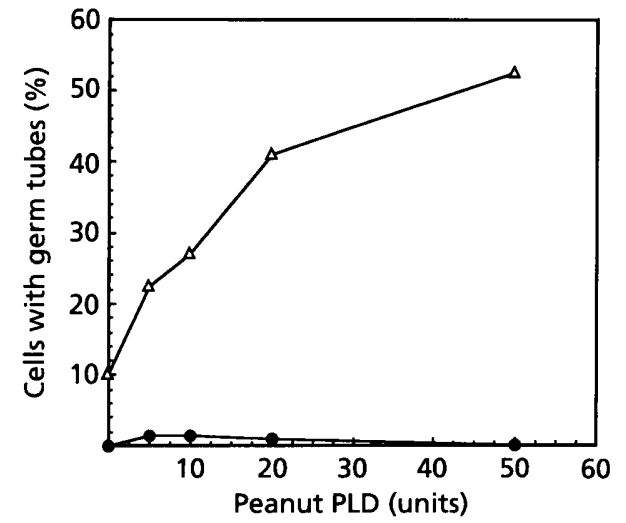

Fig. 3. Exogenous PLD can stimulate dimorphic transition. Purified peanut PLD was added to cultures of $C$. albicans at the indicated concentrations. Following a $2 \mathrm{~h}$ incubation at $30^{\circ} \mathrm{C}$ (O) or $39^{\circ} \mathrm{C}(\triangle)$, the percentage of cells with germ tubes in each culture was determined by direct microscopic enumeration. The results presented are from a single representative experiment.

\section{CaPLD1 is required for dimorphic transition}

The involvement of CaPLD1 in dimorphic transition was investigated using three separate approaches. The addition of exogenous PLD to culture medium has been used to artificially enhance the generation of phosphatidic acid, thus amplifying the effect of endogenous PLD activity (Kaszkin et al., 1996). Commercially purified peanut PLD was added to cultures growing in YPD at 30 and $39^{\circ} \mathrm{C}$. After $2 \mathrm{~h}$, the percentage of germ tubes present in each culture was determined by direct microscopic enumeration (Fig. 3). The exogenous PLD had little effect on cells cultured at $30^{\circ} \mathrm{C}$ but produced a dose-dependent stimulation of germ tube formation at $39^{\circ} \mathrm{C}$.

The presence of alcohols in the culture medium has been shown to attenuate PLD-dependent responses in mammalian cells due to the formation of phosphatidylalcohol at the expense of phosphatidic acid (Kaszkin et al., 1996). Therefore, we assessed the effect of alcohols on

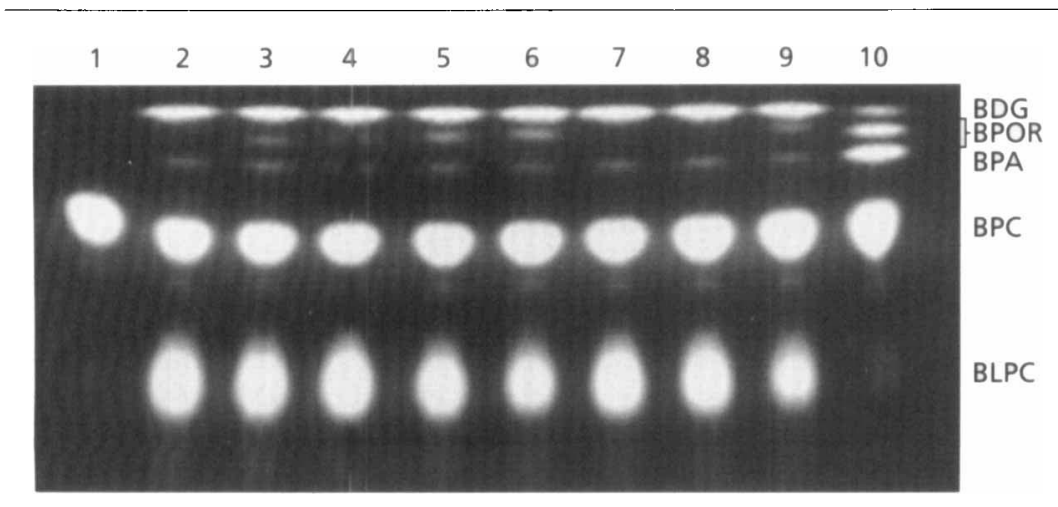

Fig. 2. Use of alcohols by CaPLD1. The reaction in lane 1 did not contain any extract and the reaction in lane 10 contained 5 units peanut PLD incubated with $0.5 \%(\mathrm{v} / \mathrm{v})$ butanol. In the remaining lanes, extract of $C$. albicans cells was incubated with different alcohols, present at $0.5 \% \quad(\mathrm{v} / \mathrm{v})$. Lanes: 2, no alcohol; 3, methanol; 4, ethanol; 5, propanol; 6, butanol; 7, 2-propanol; 8, 2-methyl-1propanol; 9, 3-methyl-1-butanol. The separation was performed on plastic-backed silica gel 60 plates (EM Science). BLPC, BODIPY-lysophosphatidylcholine. 


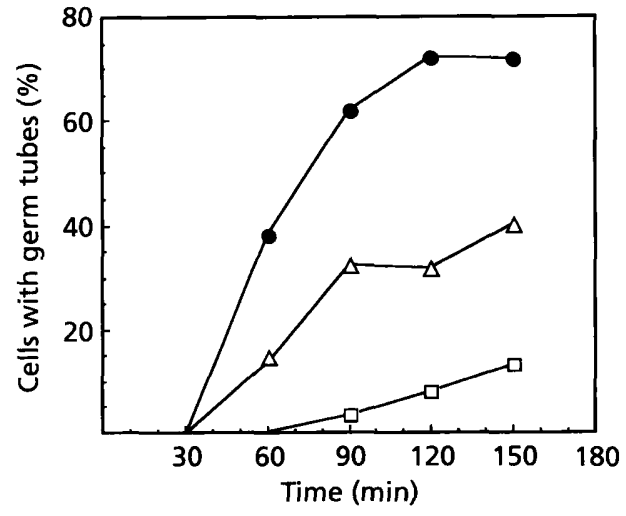

Fig. 4. Presence of alcohols can inhibit the formation of germ tubes. Cells were induced to form germ tubes by the addition of FBS to $25 \%(\mathrm{v} / \mathrm{v})$ at $39^{\circ} \mathrm{C}$ and the appearance of germ tubes was monitored microscopically. No alcohol was added to the control cells (O); either 1-propanol $(\square)$ or 2-propanol $(\triangle)$ was added, as indicated, to a final concentration of $0.5 \%(\mathrm{v} / \mathrm{v})$. The results presented are from a single representative experiment.

dimorphic transition (Fig. 4). A single culture was split into three cultures and FBS was added to $25 \%(\mathrm{v} / \mathrm{v})$ final concentration to induce the formation of germ tubes. One culture served as a control for the effects of alcohol and received no further additions. A second culture received 1-propanol to a final concentration of $0.5 \%$ $(\mathrm{v} / \mathrm{v})$ while the third culture received 2-propanol to $0.5 \%(\mathrm{v} / \mathrm{v}) .1$-Propanol is a very good substrate for the transphosphatidylation reaction while 2-propanol is a very poor substrate. Both alcohols reduced the rate of appearance of hyphal cells (Fig. 4). Consistent with the relative ability of CaPLD1 to use the alcohols, 2propanol, the poor substrate, had a less pronounced effect on dimorphic transition than did 1-propanol, the good substrate.

The analysis of endogenous CaPLD1 activity was investigated for additional support of a role for CaPLD1 in dimorphic transition. A culture growing at $30^{\circ} \mathrm{C}$ was supplemented with FBS to $25 \%(\mathrm{v} / \mathrm{v})$ and was shifted to $39^{\circ} \mathrm{C}$. Samples were withdrawn at various times after the temperature shift and membranes were prepared and assayed for CaPLD1 activity. Fig. 5(a) shows that the level of CaPLD1 activity increased following the addition of FBS and the shift in temperature. The increase in activity appeared as the germ tubes appeared in the culture. The level of increase in CaPLD1 activity was slightly less than twofold. While this induction is small, it is consistent with the level of induction seen with ScPLD1 when S. cerevisiae cells are exposed to sporulation medium (Ella et al., 1995). One possible explanation for the increase in PLD activity measured in the assay is the presence of a PLD in the FBS. Incubation of BPC with serum failed to produce any detectable BPA (data not shown).

FBS could alter CaPLD1 activity through a number of different responses, not just the induction of dimorphic transition. To clarify the correlation between CaPLD1

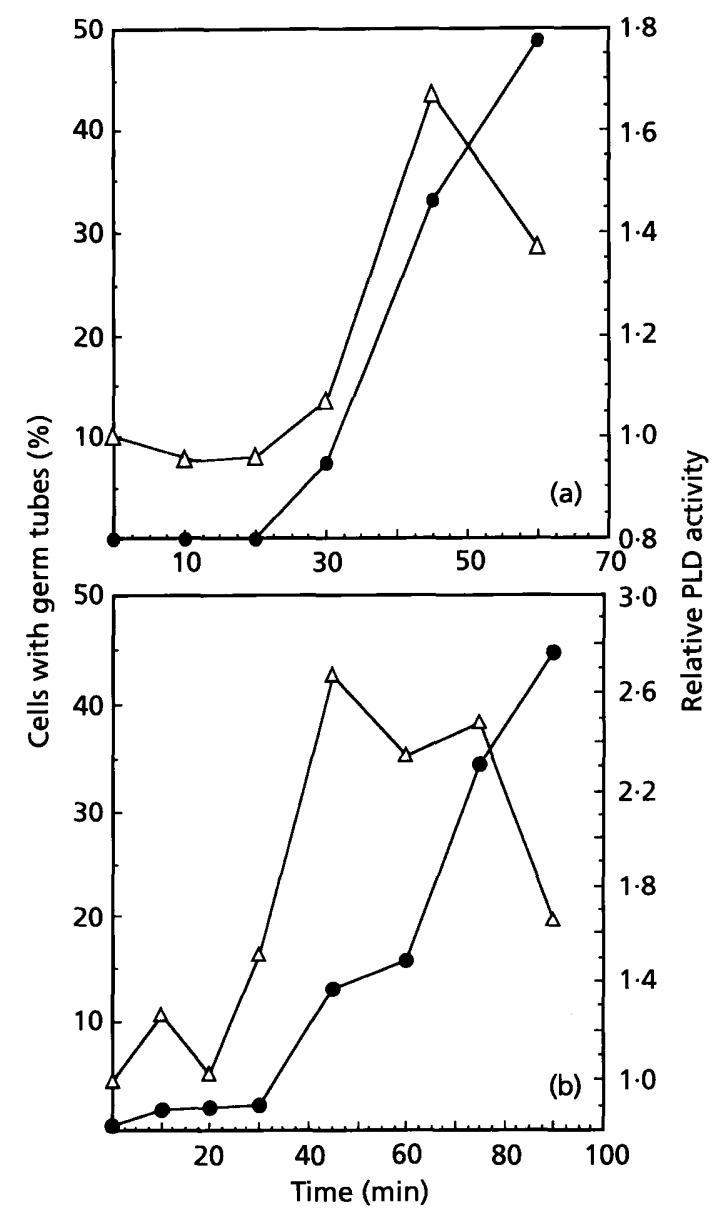

Fig. 5. CaPLD1 activity is induced during dimorphic transition. (a) Cells were induced to form germ tubes by the addition of FBS and shift from 30 to $39^{\circ} \mathrm{C}$. The level of CaPLD1 in wholecell extracts of cells from various time-points after induction was determined $(\triangle)$. The percentage of cells that had formed germ tubes was determined for each sample by direct counting (O). The data presented in the figure are derived from a single representative experiment because the rate and extent of germination varies from culture to culture. (b) Cells were induced to form germ tubes by the addition of $N$ acetylglucosamine and shift from 30 to $39^{\circ} \mathrm{C}$. Samples were taken and analysed as in (a). Cells with germ tubes; $\triangle$, relative PLD activity.

activity and dimorphic transition, the previous experiment was repeated with a more defined inducer. Culturing C. albicans cells at $39^{\circ} \mathrm{C}$ in the presence of $2.5 \mathrm{mM} \mathrm{N}$-acetylglucosamine is sufficient to induce the appearance of germ tubes (Paveto et al., 1990). CaPLD1 activity was observed to increase and then decrease with similar kinetics when transition was induced with temperature and $\mathrm{N}$-acetylglucosamine (Fig. $5 \mathrm{~b}$ ).

The change in CaPLD1 activity seen in these experiments could indicate changes associated with adaptation to growth at elevated temperature. To determine whether this was the case, the level of CaPLD1 activity in cells cultured at $39^{\circ} \mathrm{C}$ for an extended time was compared to a parallel culture maintained at $30^{\circ} \mathrm{C}$. The level of 
CaPLD1 activity was actually $23 \%$ lower in cells cultured overnight at $39^{\circ} \mathrm{C}$ relative to cells cultured at $30^{\circ} \mathrm{C}$. Therefore, the observed stimulation in CaPLD1 activity correlated with the induction of germ tubes and not with growth at elevated temperatures.

\section{DISCUSSION}

This is the first report of PLD activity in the opportunistic fungal pathogen C. albicans. In light of the number of organisms possessing more than one form of PLD, we have designated the enzyme described in this report CaPLD1. This enzyme is membrane-associated and capable of performing a transphosphatidylation reaction in the presence of primary alcohols. CaPLD1 is stimulated by growth on galactose or acetate but inhibited by growth on glycerol. CaPLD1 activity is stimulated during dimorphic transition and induced by elevated temperature and either serum or $\mathrm{N}$-acetylglucosamine. Previous reports on phospholipase activity in C. albicans (for example, Barrett-Bee et al., 1985; Ibrahim et al., 1995) have focused on secreted enzymes that may facilitate tissue invasion, which may profoundly augment virulence (Ibrahim et al., 1995). None of these earlier reports have described PLD activity associated with C. albicans. CaPLD1 activity described in this report appears to be required for the expression of another virulence factor, the completion of transition from yeast to hyphal cell morphology. This conclusion is based on the ability of exogenous PLD to stimulate the process, the ability of a primary alcohol in the medium to attenuate the process, and the stimulation of CaPLD1 activity by inducers of the process. A direct effect of the alcohol on dimorphic transition cannot be excluded. For example, the alcohols could modify the cell membrane by interacting with the membrane lipids, thus altering the cell's ability to change shape.

C. albicans and S. cerevisiae are very similar in many ways. Both are budding yeasts capable of undergoing dimorphic transitions to elongated growth patterns which result in the formation of germ tubes or pseudohyphae, respectively (Soll, 1986; Gimeno et al., 1992). The similarity is such that many C. albicans genes have been cloned by complementation of the homologous mutants in S. cerevisiae (Kurtz et al., 1988). Therefore, it is not surprising that CaPLD1 shares many features with ScPLD1. Both enzymes are membrane-associated, capable of transphosphatidylation with alcohols, and regulated by carbon source. The major difference between these two enzymes is their physiological role, and even in this regard there is similarity.

Diploid S. cerevisiae cells experiencing nutrient deprivation, particularly lack of nitrogen and glucose, will undergo meiosis and sporulation to form haploid spores. ScPLD1 is stimulated in response to conditions that induce this differentiation and is essential for the completion of the process (Ella et al., 1995; Waksman $e t$ al., 1996; Rose et al., 1995). C. albicans does not undergo meiosis and sporulation to form haploid spores; consequently, CaPLD1 must play a different role. In a similar manner, CaPLD1 activity is stimulated by inducers of dimorphic transition and is essential for the completion of the change. In a possibly similar manner, a phosphatidylinositol/phosphatidylcholine transfer protein is required for dimorphic transition in the yeast Yarrowia lipolytica (Lopez et al., 1994). Like PLDs, phosphatidylinositol/phosphatidylcholine transfer proteins can alter the phospholipid composition of secretory vesicles to control physiological processes. These findings indicate the importance of lipid composition and signalling in the control of differentiation in fungi. The involvement of CaPLD1 in dimorphic transition and of ScPLD1 in sporulation suggests that one role for fungal PLDs may be the conversion of external stimuli into developmental changes. A role for PLD activity in differentiation is not limited to fungi. PLD plays important roles in the differentiation of rat preovulatory follicles (Liscovitch \& Amsterdam, 1989; Amsterdam et al., 1994) and murine haematopoietic cells (Clejan et al., 1996). The relative simplicity of the fungal systems will facilitate the dissection of the role of PLD in eukaryotic cell differentiation.

\section{REFERENCES}

Amsterdam, A., Dantes, A. \& Liscovitch, M. (1994). Role of phospholipase-D and phosphatidic acid in mediating gonadotropin-releasing hormone-induced inhibition of preantral granulosa cell differentiation. Endocrinology 135, 1205-1211.

Balboa, M. A. \& Insel, P. A. (1995). Nuclear phospholipase D in Madin-Darby canine kidney cells. Guanosine $5^{\prime}$-O-(thiotriphosphate)-stimulated activation is mediated by RhoA and is downstream of protein kinase C. J Biol Chem 270, 29843-29847.

Barrett-Bee, K., Hayes, Y., Wilson, R. G. \& Ryley, J. F. (1985). A comparison of phospholipase activity, cellular adherence and pathogenicity of yeasts. J Gen Microbiol 131, 1217-1221.

Brown, H. A., Gutowski, S., Moomaw, C. R., Slaughter, C. \& Sternweis, P. C. (1993). ADP-ribosylation factor, a small GTPdependent regulatory protein, stimulates phospholipase D activity. Cell 75, 1137-1144.

Carnero, A., Dolfi, F. \& Lacal, J. C. (1994). Ras-p21 activates phospholipase D and A2, but not phospholipase C or PKC, in Xenopus laevis oocytes. J Cell Biochem 54, 478-486.

Clejan, S., Mallia, C., Vinson, D., Dotson, R. \& Beckman, B. S. (1996). Erythropoietin stimulates G-protein-coupled phospholipase $\mathrm{D}$ in haematopoietic target cells. Biochem J 314, 853-860.

Cockcroft, S., Thomase, G. M. H., Fensome, A., Geny, B., Cunningham, E., Gout, I., Hiles, I., Totty, N. F., Truong, O. \& Hsuan, J. J. (1994). Phospholipase D: a downstream effector of ARF in granulocytes. Science 263, 523-526.

Conricode, K. M., Brewer, K. A. \& Exton, J. H. (1992). Activation of phospholipase $\mathrm{D}$ by protein kinase C. Evidence for a phosphorylation-independent mechanism. J Biol Chem 267, 7199-7202.

Ella, K. M., Dolan, J. W. \& Meier, K. E. (1995). Characterization of a regulated form of phospholipase D in the yeast Saccharomyces cerevisiae. Biochem J 307, 799-805.

Ella, K. M., Dolan, J. W., Qi, C. \& Meier, K. E. (1996). Characterization of Saccharomyces cerevisiae deficient in expression of phospholipase D. Biochem J 314, 15-19.

Exton, J. H. (1990). Signaling through phosphatidylcholine breakdown. J Biol Chem 265, 1-4. 
Gimeno, C. J., Ljungdahl, P. O., Styles, C. A. \& Fink, G. R. (1992). Unipolar cell divisions in the yeast $S$. cerevisiae lead to filamentous growth: regulation by starvation and RAS. Cell 68, 1077-1090.

Ha, K.-S. \& Exton, J. H. (1993). Activation of actin polymerization by phosphatidic acid derived from phosphatidylcholine in IIC9 fibroblasts. J Cell Biol 123, 1789-1796.

Hammond, S. M., Altshuller, Y. M., Sung, T.-C., Rudge, S. A., Rose, K., Engebrecht, J., Morris, A. J. \& Frohman, M. A. (1995). Human ADP-ribosylation factor-activated phospholipase D defines a new and highly conserved gene family. J Biol Chem 270 , 29640-29643.

Heller, M. (1978). Phospholipase D. Adv Lipid Res 16, 267-326. Honigberg, S. M., Conicella, C. \& Espositio, R. E. (1992). Commitment to meiosis in Saccharomyces cerevisiae: involvement of the SPO14 gene. Genetics 130, 703-716.

Ibrahim, A. S., Mirbod, F., Filler, S. G., Banno, Y., Cole, G. T., Kitajima, Y., Edwards, J. E., Jr, Nozawa, Y. \& Ghannoum, M. A. (1995). Evidence implicating phospholipase as a virulence factor of Candida albicans. Infect Immun 63, 1993-1998.

Jenkins, G. H., Fisette, P. L. \& Anderson, R. A. (1994). Type I phosphatidylinositol 4-phosphate 5-kinase isoforms are specifically stimulated by phosphatidic acid. J Biol Chem 269, 1154711554.

Jiang, H., Luo, J.-Q., Urano, T., Frankel, P., Lu, Z., Foster, D. A. \& Feig, L. A. (1995). Involvement of Ral GTPase in v-Src-induced phospholipase D activation. Nature 378, 409-412.

Jimenez, B., del Peso, L., Montaner, S., Esteve, P. \& Lacal, J. C. (1995). Generation of phosphorylcholine as an essential event in the activation of Raf-1 and MAP-kinases in growth factorinduced mitogenic stimulation. J Cell Biochem 57, 141-149.

Kanfer, J. N. (1980). The base exchange enzymes and phospholipase D of mammalian tissue. Can J Biochem 58, 1370-1380.

Kaszkin, M., Richards, J. \& Kinzel, V. (1996). Phosphatidic acid mobilization by phospholipase D is involved in the phorbol 12myristate 13-acetate-induced G2 delay in A431 cells. Biochem J 31, 129-138.

Kurtz, M. B., Kirsch, D. R. \& Kelly, R. (1988). The molecular genetics of Candida albicans. Microbiol Sci 5, 58-63.

Liscovitch, M. \& Amsterdam, A. (1989). Gonadotropin-releasing hormone activates phospholipase D in ovarian granulosa cells: possible role in signal transduction. $J$ Biol Chem 264, 1176211767.

Liscovitch, M., Chalifa, V., Pertile, P., Chen, C.-S. \& Cantley, L. C. (1994). Novel function of phosphatidylinositol 4,5-bisphosphate as a cofactor for brain membrane phospholipase D. J Biol Chem 269, 21403-21406.

Lopez, I., Burns, D. J. \& Lambeth, J. D. (1995). Regulation of phospholipase $\mathrm{D}$ by protein kinase $\mathrm{C}$ in human neutrophils. Conventional isoforms of protein kinase $\mathrm{C}$ phosphorylate a phospholipase D-related component in the plasma membrane. J Biol Chem 270, 19465-19472.

Lopez, M. C., Nicaud, J.-M., Skinner, H. B., Vergnolle, C., Kader, J. C., Bankaitis, V. A. \& Gaillardin, C. (1994). A phosphatidylinositol/phosphatidylcholine transfer protein is required for differ- entiation of the dimorphic yeast Yarrowia lipolytica from the yeast to mycelial form. J Cell Biol 124, 113-127.

Massenburg, D., Han, J.-S., Liyanage, M., Patton, W. A., Rhee, S. G., Moss, J. \& Vaughan, M. (1994). Activation of rat brain phospholipase D by ADP-ribosylation factors 1, 5, and 6: separation of ADP-ribosylation factor-dependent and oleatedependent enzymes. Proc Natl Acad Sci USA 91, 11718-11722.

Mayr, J. A., Kohlwein, S. D. \& Paltauf, F. (1996). Identification of a novel, $\mathrm{Ca}(2+)$-dependent phospholipase $\mathrm{D}$ with preference for phosphatidylserine and phosphatidylethanolamine in Saccharomyces cerevisiae. FEBS Lett 393, 236-240.

Moritz, A., De Graan, P. N. E., Gispen, W. H. \& Wirtz, K. W. A. (1992). Phosphatidic acid is a specific activator of phosphatidylinositol-4-phosphate kinase. J Biol Chem 267, 7207-7210.

Morlock, K. R., McLaughlin, J. J., Lin, Y.-P. \& Carman, G. M. (1991). Phosphatidate phosphatase from Saccharomyces cerevisiae: isolation of $45-$ and $104-\mathrm{kDa}$ forms of the enzyme that are differentially regulated by inositol. J Biol Chem 266, 3586-3593.

Ohguchi, K., Banno, Y., Nakashima, S. \& Nozawa, Y. (1995). Activation of membrane-bound phospholipase D by protein kinase C in HL60 cells: synergistic action of a small GTP-binding protein RhoA. Biochem Biophys Res Commun 211, 306-311.

Paveto, C., Egidy, G., Galvagno, M. A. \& Passeron, S. (1990). A guanine nucleotide-sensitive, glucagon-stimulated adenylyl cyclase in Candida albicans: effect of glucagon on cell morphology. Biochem Biophys Res Commun 167, 1177-1183.

Rose, K., Rudge, S. A., Frohman, M. A., Morris, A. J. \& Engebrecht, J. (1995). Phospholipase D signaling is essential for meiosis. Proc Natl Acad Sci USA 92, 12151-12155.

Sherman, F. (1991). Getting started with yeast. Methods Enzymol 194, 3-21.

Soll, D. R. (1986). The regulation of cellular differentiation in the dimorphic yeast Candida albicans. BioEssays 5, 5-11.

Song, J. \& Foster, D. A. (1993). v-Src activates a unique phospholipase D activity that can be distinguished from the phospholipase D activity activated by phorbol esters. Biochem J 294, 711-717.

Waksman, M., Eli, Y., Liscovitch, M. \& Gerst, J. E. (1996). Identification and characterization of a gene encoding phospholipase D activity in yeast. $J$ Biol Chem 271, 2361-2364.

Waksman, M., Tang, X., Eli, Y., Gerst, J. E. \& Liscovitch, M. (1997). Identification of a novel $\mathrm{Ca}^{2+}$-dependent, phosphatidylethanolamine-hydrolyzing phospholipase $\mathrm{D}$ in yeast bearing a disruption in PLD1. J Biol Chem 272, 36-39.

Wang, X., Xu, L. \& Zheng, L. (1994). Cloning and expression of phosphatidylcholine-hydrolyzing phospholipase D from Ricinus communis L. J Biol Chem 269, 20312-20317.

Wu, W.-I., Lin, Y.-P., Wang, E., Merrill, A. H. \& Carman, G. M. (1993). Regulation of phosphatidate phosphatase activity from the yeast Saccharomyces cerevisiae by sphingoid bases. J Biol Chem 268, 13830-13837.

Received 24 March 1997; revised 8 July 1997; accepted 22 July 1997. 